\title{
SISTEMA DE INFORMAÇÃO PARA GERAÇÃO DE ENERGIA EÓLICA
}

Julio Cesar Pinheiro Pires

Universidade Federal do Rio Grande do Sul

Universidade Federal de Santa Maria

julio.pires@ufsm.br

Branca Freitas de Oliveira

Universidade Federal do Rio Grande do Sul

branca@ufrgs.br

Resumo: Este artigo aborda o desenvolvimento de um sistema de informação que mostra os benefícios da utilização de geração distribuída de energia elétrica. O sistema desenvolvido conta com um aplicativo de simulação, versão para microcomputadores, que informa e auxilia o usuário na montagem de um projeto de microgeração de energia com Turbina Eólica de Pequeno Porte (TEPP). $O$ aplicativo está funcionando com acesso livre a partir de um servidor da Universidade onde foi desenvolvido. Espera-se, com a aplicação do método e elaboração do sistema, atingir número expressivo de simulações realizadas. Acredita-se que a realização de simulações no aplicativo proposto possa auxiliar a divulgar os benefícios da geração distribuída de energia elétrica no Brasil.

Palavras-chave: Design da informação, Energia eólica, Aplicativo Web, Geração distribuída.

Abstract: This article discusses the development of an information system that shows the benefits of using distributed power generation. The system developed has a simulation APP, version for microcomputers, which advises and assists the user in mounting an energy microgeneration project with Small Wind Turbine(SWT).The APP is working with free access from a server of the University where it was made. It is expected that with the application of the method and development of the system a significant number of users simulations are achieved. It is believed that performing simulations in the proposed application can help to promote the benefits of distributed power generation in Brazil.

Keywords: Information design, Wind energy, Web APP, Distributed power generation. 


\section{INTRODUÇÃO}

Energia elétrica convertida por fontes renováveis tem ganho cada vez mais espaço na matriz energética brasileira. Em 2016, o governo federal do Brasil estima aumento de $40 \mathrm{GW}$ de energia elétrica convertida por geradores eólicos (ANEEL, 2016).

Apesar desse crescimento, segundo o relatório do GWEC (2013), problemas como a distribuição de energia, logística, infraestrutura entre outros, preocupam o setor e fazem crescer a importância de investimento em geração distribuída de energia elétrica.

Geração distribuída não é considerada como um tema novo. Algumas políticas já foram elaboradas a fim de regulamentar essa pratica no Brasil. Em abril de 2012 a ANEEL publicou a Resolução Normativa 482 de 17 de abril de 2012, que estabelece as condições gerais para acesso de mini e microgeração distribuída ao sistema de distribuição de energia elétrica. Além disso, a resolução trata do sistema de compensação de energia elétrica (CGEE, 2012). Para ser considerada central microgeradora esta deve ter potência instalada igual ou menor a $100 \mathrm{~kW}$. Já as centrais minigeradoras devem ter potência superior a $100 \mathrm{~kW}$ e igual ou inferior a $1 \mathrm{MW}$. Além disso, outra condição imposta pela ANEEL é que a geração seja feita através de fontes renováveis como solar, eólica, biomassa, entre outras.

$O$ incentivo no recebimento de créditos de energia para produtores que geram mais energia do que consomem representa um potencial atrativo no contexto da geração distribuída. Essa prática elimina a obrigação do uso de baterias acumuladoras para se utilizar energia em períodos em que não se pode gerar, no caso da falta de vento para turbinas eólicas, por exemplo.

Apesar de existir no Brasil legislação específica que regulamenta microgeração de energia (ANEEL, 2012), essa prática não está disseminada e tampouco é de conhecimento da maioria das pessoas.

A desinformação sobre geração própria de energia pode ser a principal causa da não utilização de equipamentos de conversão de eletricidade em nível residencial.

Este artigo trata do desenvolvimento de um sistema de informação que mostra os benefícios da utilização de geração distribuída de energia elétrica. O sistema terá um aplicativo de simulação que irá informar, responder e auxiliar ao usuário na montagem de um projeto de microgeração de energia com Turbina Eólica de Pequeno Porte (TEPP).

O método utilizado para criação do sistema é caracterizado pela obtenção de requisitos dispostos em um mapa e organização de um modelo para responder ao usuário, retirando do mapa as informações necessárias para realizar essa tarefa. Além disso, o método prevê o recebimento de informações do próprio usuário para realizar operações e devolver informações requeridas.

O sistema é essencialmente informativo. A primeira versão do aplicativo tem caráter avaliativo e experimental, necessitando assim de feedback de usuários.

\section{DESIGN E SISTEMAS DE INFORMAÇÃO}

Sistemas de informação e comunicação, como o próprio nome diz, tratam de conduzir informação às pessoas. Informações que podem ter diversas finalidades. Normalmente existe uma demanda por informações advinda diretamente das pessoas. 
Desta forma uma pessoa, por exemplo, pode se beneficiar de um aplicativo de celular para obter informações relativas ao horário em que o transporte coletivo passará em cada ponto de parada. Neste exemplo, existe o sujeito pessoa, o produto aplicativo e o benefício informação.

Sistemas de informação criados para população em geral, como usuários finais, tendem a necessitar de características em comum para atingir plenamente seus objetivos. Esse tipo de sistema pode ser considerado produto, sendo assim analisado sob a ótica do design, que nesse caso se propõe como uma ciência que guia o desenvolvimento e todo o ciclo do produto, desde a necessidade de sua existência até sua obsolescência.

Design da informação, segundo Horn (1999) é a arte e a ciência de preparação da informação, possibilitando seu uso pelo homem.

Segundo Friedman (2003), design se tornou uma disciplina generalizada que pode ser aplicada a processos, meios de comunicação e informação.

Design da informação ou projeto de produto para informação foi utilizado nesta pesquisa para elaboração de um sistema de informação para geração de energia eólica residencial. $O$ inicio do processo consiste na criação de um mapa-modelo dos requisitos básicos, onde é apresentado um conjunto de informações que formam o método adotado para o sistema proposto.

O mapa é a parte analítica e demonstra os requisitos para desenvolvimento do sistema. Esses requisitos dizem respeito desde as necessidades de existência do sistema até o projeto de artefatos, reais ou virtuais, relacionados às soluções que serão propostas. Já o modelo constitui-se da proposição de construção de conexões solucionadoras, isto é, adotar dois ou mais elementos de ação que quando trabalhando em conjunto, fornecem soluções para problemas conhecidos.

Para esta pesquisa, os elementos de ação foram classificados em: i) Nível alto concepção de idéias; ii) Nível médio - interação sistema/usuários; iii) Nível baixo equações, scripts e algoritmos, montagem do sistema.

O nível alto foi designado a partir de premissas de design para desenvolvimento de novos produtos. A interação sistema/usuários constitui a parte onde o público alvo depara-se com o produto e interage de forma efetiva. Os elementos do nível baixo têm características puramente funcionais e são de cunho privado, não fazendo parte do universo de interação com usuários.

\section{DESENVOLVIMENTO DO SISTEMA}

A elaboração do Sistema iniciou com análise do mapa-modelo. Após estabelecer quais conexões e abstrações seriam necessárias na formação do sistema concluiu-se pela elaboração de um aplicativo web-based que pudesse ser acessado livremente pelo maior número possível de usuários. As funcionalidades e respostas do aplicativo foram projetadas sem levar em conta armazenamento de dados. Esta decisão tornou o aplicativo leve e de respostas rápidas.

Segundo Aguilar (2008), sistemas de informações podem tornar-se complexos de acordo com a quantidade de dados que se pretende manusear, por isso foi elaborado, nesta pesquisa, um fluxograma com passos necessários para o atendimento de requisitos estabelecidos no mapa-modelo descrito anteriormente. A figura 1 apresenta o fluxograma em questão. 


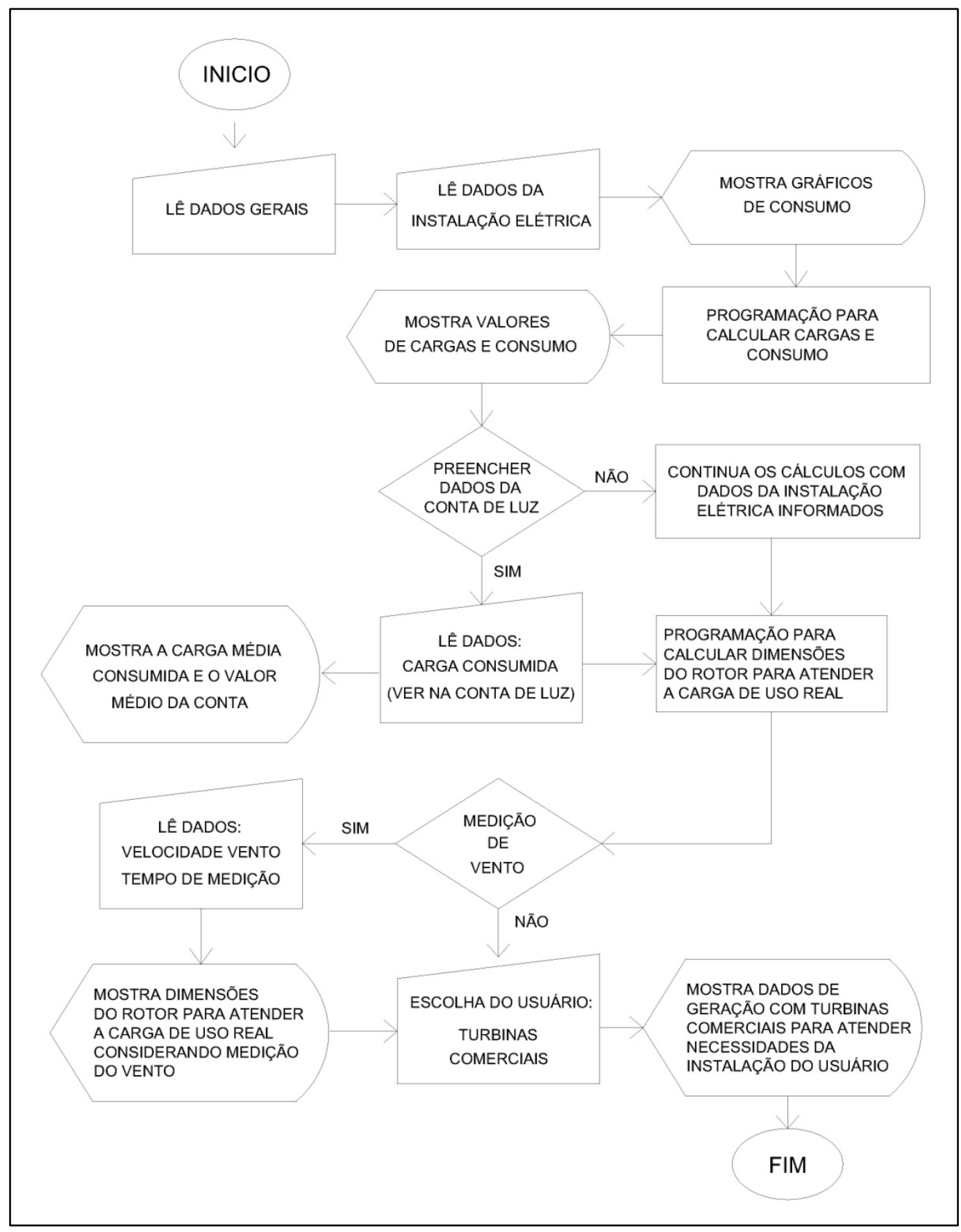

Figura 1 - Fluxograma do sistema

Fonte: Elaborado pelo autor, com base na pesquisa realizada

O fluxograma descreve o funcionamento do aplicativo, em que é possível realizar simulações diversas relacionadas com geração de energia eólica com turbina de pequeno porte.

\subsection{Concepção e funcionalidades do aplicativo de simulação}

O leiaute do aplicativo foi gerado segundo o modelo de Berlyne, citado por Baxter (2011), no qual existe um ponto ótimo de complexidade e a atratividade será maximizada. Segundo este modelo de Berlyne, um nível médio de complexidade caracteriza um leiaute mais positivo, conforme visto na figura 2. Por esse motivo 
definiu-se um leiaute em uma aba única, sem menus ou outros dispositivos deslizantes, que apresentam informações extras, fora do leiaute principal.

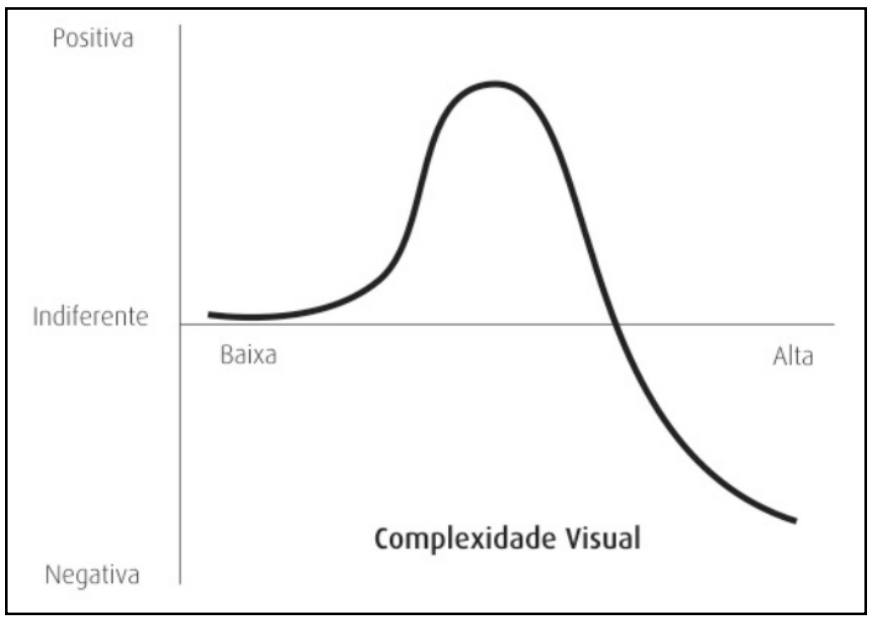

Figura 2 - Modelo de Berlyne

Fonte: Baxter, 2011

O aplicativo está dividido em 7 seções e conta com um Guia do usuário, onde se pode ter uma visão geral e aprender sobre o funcionamento de cada seção e do aplicativo como um todo.

O usuário inicia uma simulação com o preenchimento de dados gerais na seção 1 e dados específicos de sua instalação elétrica na seção 2. A figura 3 mostra as seções 1 e 2 onde a principal característica é a entrada de dados.

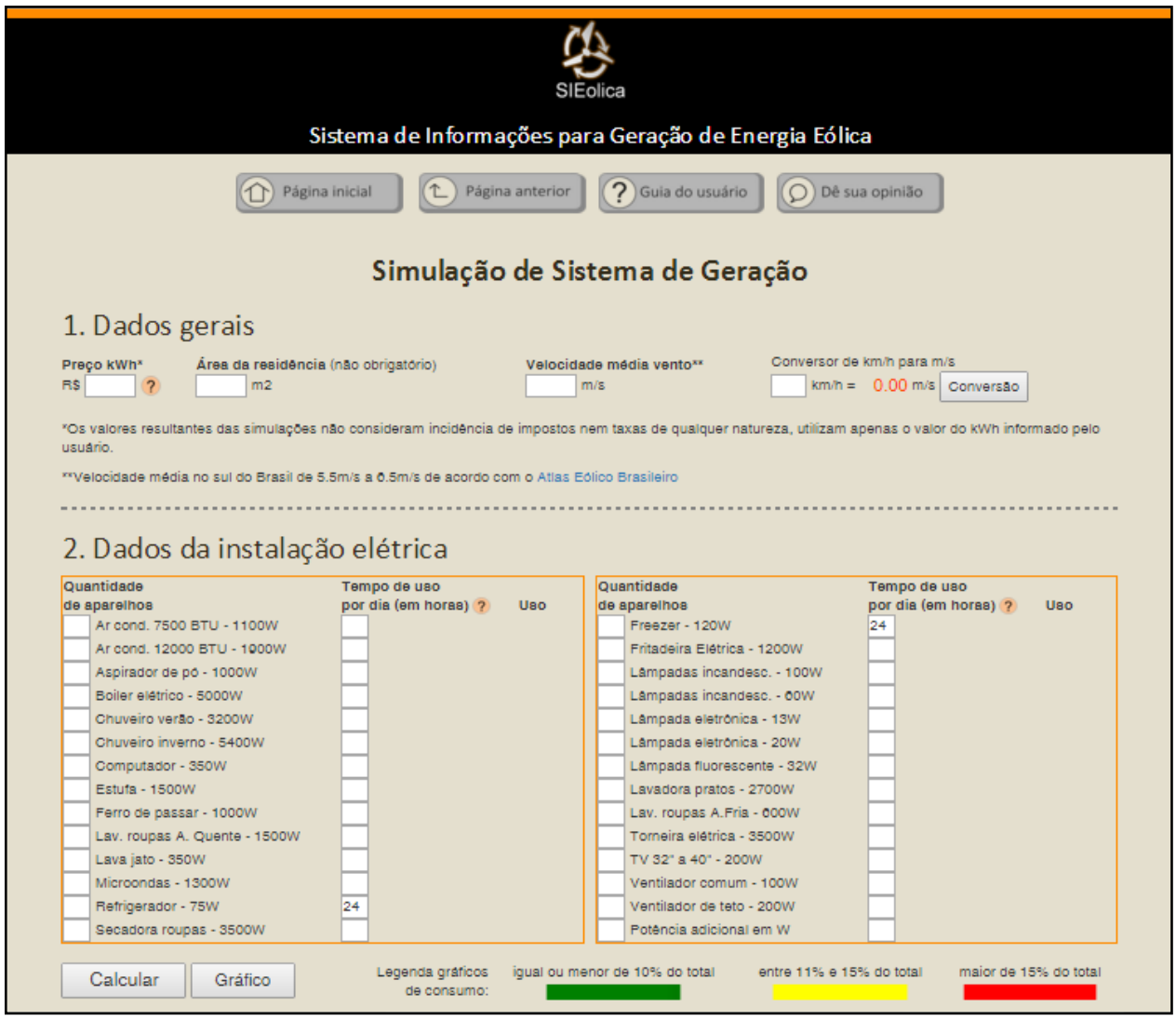

Figura 3 - Seções 1 e $\mathbf{2}$ do aplicativo de simulação

Fonte: Elaborado pelo autor, com base na pesquisa realizada 
Ainda na seção 1 foi desenvolvido um conversor de velocidade de vento, de quilômetros por hora $(\mathrm{km} / \mathrm{h})$ para metros por segundo $(\mathrm{m} / \mathrm{s})$, já que as equações do aplicativo estão escritas para receber valores de velocidade de vento em $\mathrm{m} / \mathrm{s}$.

De posse dos dados fornecidos pelo usuário, o aplicativo poderá calcular a carga instalada, a carga de demanda da edificação, informar a carga de uso real e o valor mensal que se paga de eletricidade pelo uso informado. O sistema não considera impostos e outros valores que podem estar presentes na conta de luz, sendo o cálculo feito pelo valor do quilowatt hora informado pelo usuário.

O usuário poderá clicar também no botão gráfico para gerar gráficos tipo barra e obter informações sobre seu consumo. A figura 4 mostra uma simulação realizada, onde aparecem os gráficos de consumo, a porcentagem de cada aparelho, já considerando o tempo de uso informado na seção 2 e os resultados numéricos na seção 3.

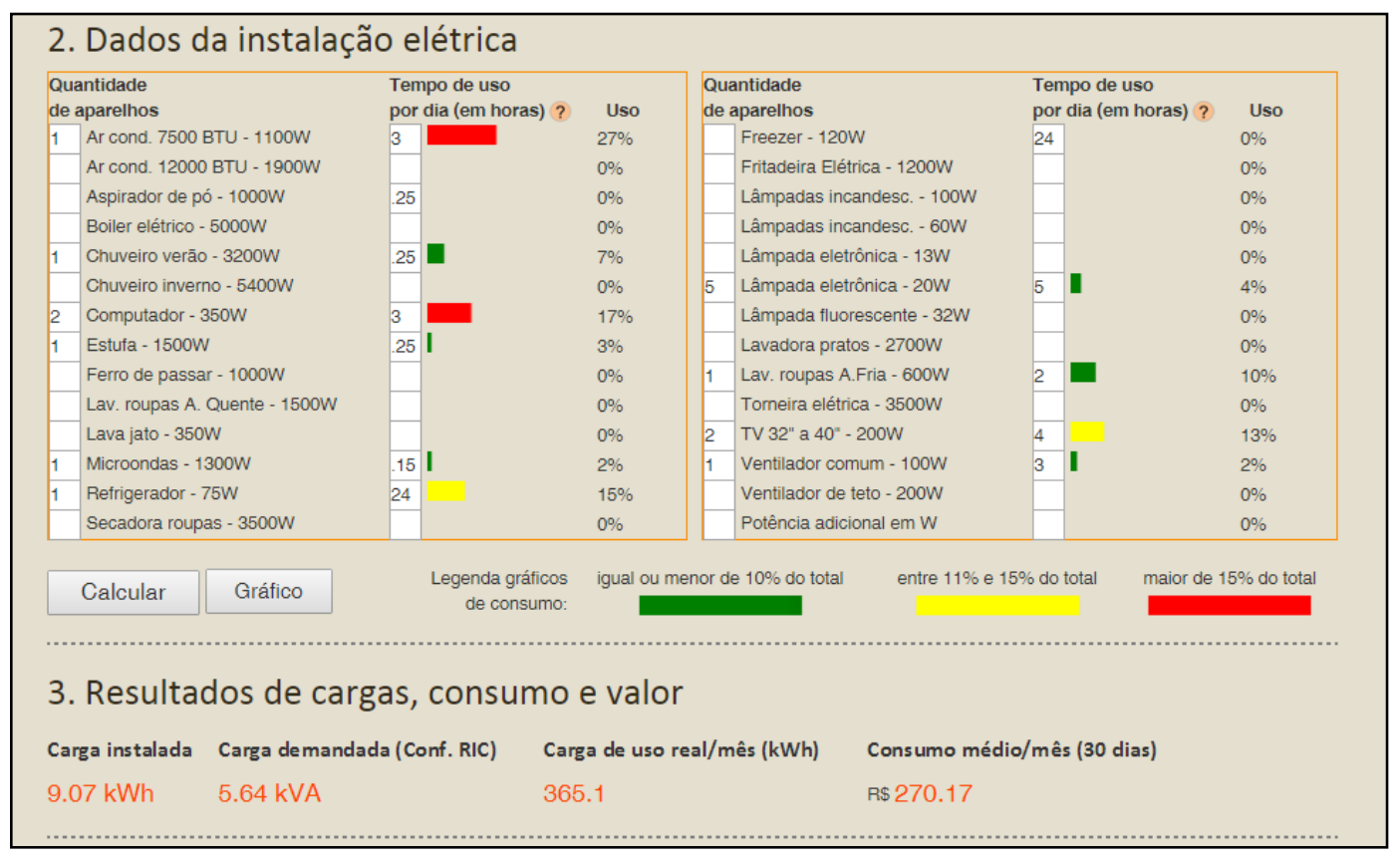

Figura 4 - Resultados de simulação

Fonte: Elaborado pelo autor, com base na pesquisa realizada

O usuário poderá também optar por preencher a carga consumida nos últimos três meses, na seção 4, de acordo com sua conta de consumo de energia elétrica, fornecida pela concessionária. Os valores inseridos nos campos "carga consumida" serão somados e divididos por 3 . Assim será gerada uma média de carga consumida e, consequentemente, um valor médio de conta de luz representando os três últimos meses de consumo.

O sistema considera o preenchimento da seção 4 para calcular as dimensões da turbina eólica. Se o usuário preencher esses dados, os valores já preenchidos na seção 2 serão desconsiderados. Se o usuário quiser simular somente com os dados da seção 2, não poderá preencher os campos da seção 4, deixando os mesmos em branco.

Após as escolhas e os preenchimentos, o aplicativo fornece, na seção 5 , as dimensões da turbina que terá de ser instalada para suprir $100 \%$ do consumo de eletricidade (figura 5). 


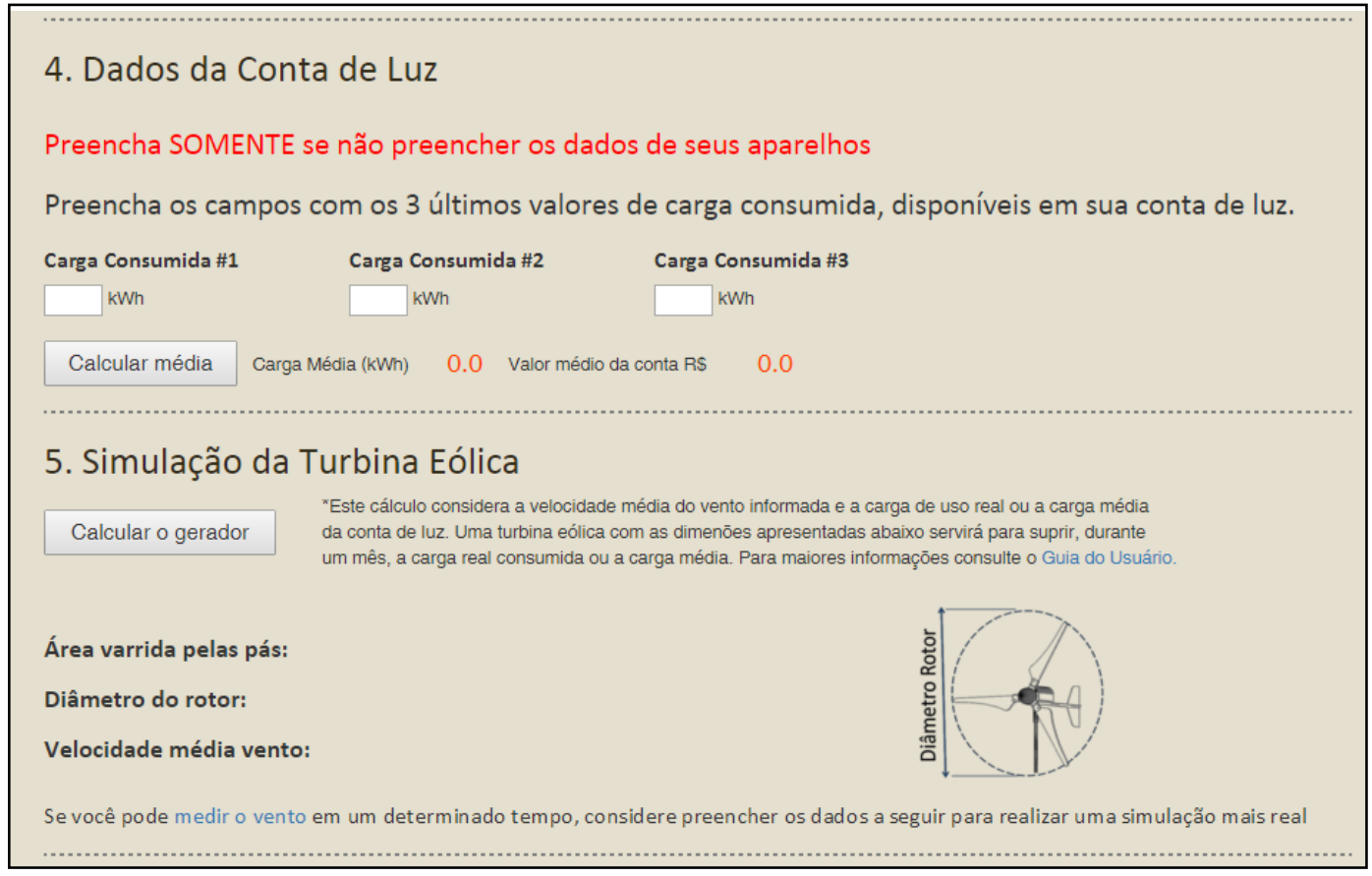

Figura 5 - Dados da conta de luz e simulação da turbina eólica

Fonte: Elaborado pelo autor, com base na pesquisa realizada

As dimensões informadas são a área varrida pelas pás (área do circulo imaginário formado pelo movimento de rotação das pás do rotor), o diâmetro do rotor (diâmetro do mesmo circulo imaginário, ou seja, aproximadamente duas vezes o comprimento da pá) e a velocidade média do vento que foi considerada para os cálculos. Essa velocidade é a mesma que o usuário preencheu na seção 1 do aplicativo.

A velocidade do vento é um dado importante para previsão de conversão de energia com aerogeradores. A equação (1) que prevê a potência disponível no vento para uma turbina eólica de eixo horizontal considera velocidade do vento ao cubo, ou seja, para prever a eficiência da turbina, deve-se considerar velocidade do vento mais próxima da realidade do local da instalação da turbina eólica. Na eq. (1), $\rho$ é a densidade do ar e $A$ a área da seção transversal onde percorre um fluxo de ar com velocidade $v$. A fração constante 16/27 é o limite de Betz (Pires, 2010).

$$
P_{\text {dis }}=\frac{1}{2} \rho A v^{3}\left(\frac{16}{27}\right)
$$

Por esse motivo foi desenvolvido no aplicativo uma seção onde o usuário pode realizar medição de velocidade do vento no local onde pretende instalar sua turbina (figura 6). Se fizer isso, o mesmo poderá preencher os campos da seção 6 com seus dados e simular novamente. 


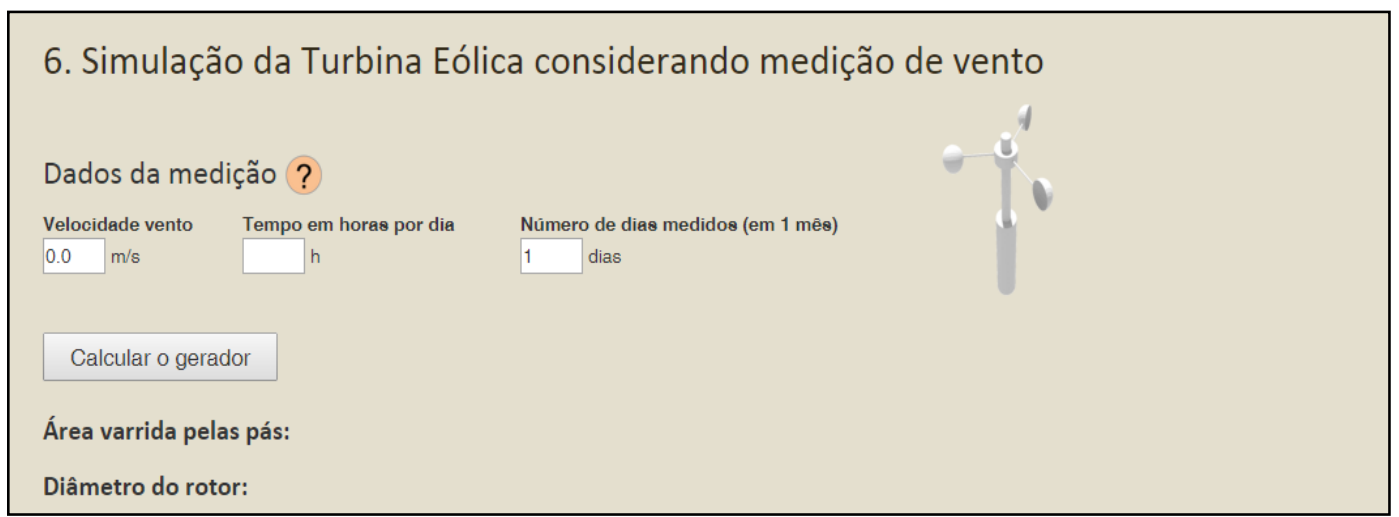

Figura 6 - Formulário de dados medição do vento

Fonte: Elaborado pelo autor, com base na pesquisa realizada

Os campos de preenchimento de velocidade do vento foram concebidos de forma que o usuário possa informar sua medição feita em horas por dia e dias por mês. O sistema irá considerar a velocidade medida no período de medição. No restante do tempo o sistema considerará a velocidade média informada na seção 1 . Se - usuário desejar considerar apenas a velocidade medida, poderá informar a velocidade média da seção 1 como 0 (zero).

A figura 7 mostra a parte do script onde consta essa lógica de processamento. Seguindo essa lógica, foi definida uma variável chamada 'valorum', declarada na linha 10 e uma variável chamada 'valordois', declarada na linha 11.

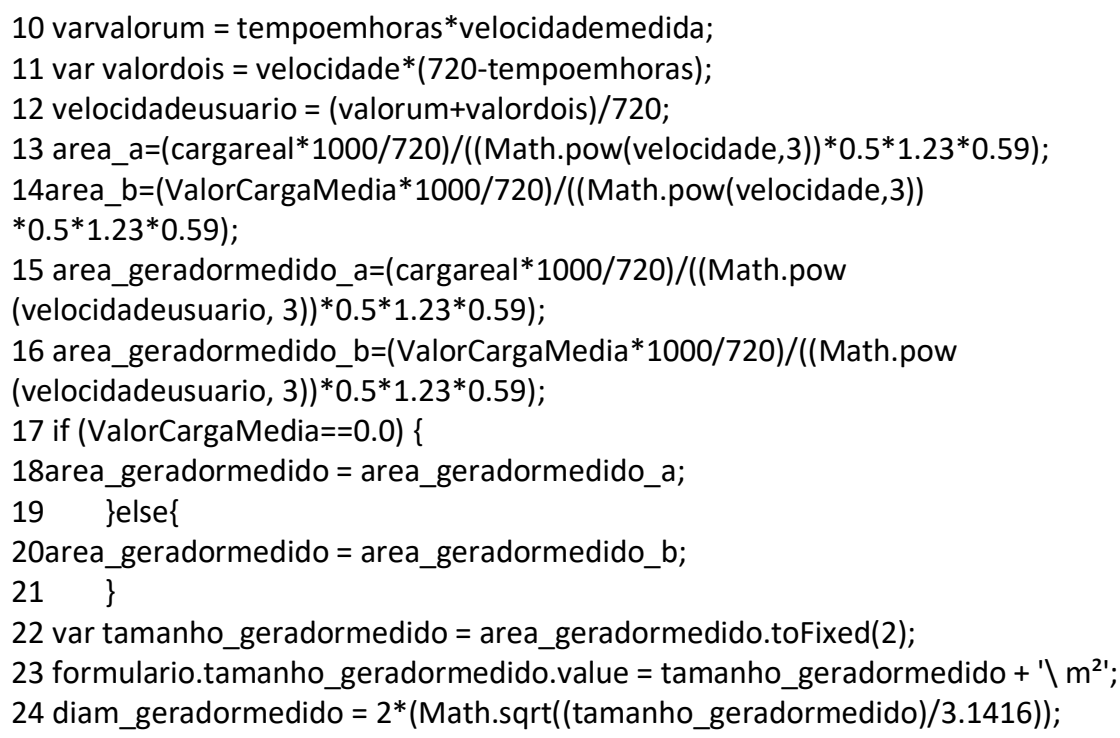

Figura 7 - Script considerando medição de vento

Fonte: Elaborado pelo autor, com base na pesquisa realizada

A variável 'valorum' pega o tempo de medição (em horas e por mês) e multiplica pela velocidade medida. Esses dados o usuário preenche na seção 6 . A variável 'valordois' considera a velocidade média informada na seção 1 pelo usuário e multiplica pelo tempo restante, ou seja, o tempo em que o usuário não mediu o vento.

A velocidade que será usada no cálculo das características da turbina será a 'velocidadeusuario', definida como uma constante na linha 12 do script apresentado 
na figura 7. Essa constante soma as variáveis 'valorum' e 'valordois' e divide pelo numero de horas em um mês. Desta maneira retira o item "tempo" da equação e o que sobra é apenas "velocidade", que será usada no cálculo da potência da turbina eólica.

Se o usuário deseja considerar apenas sua medição de vento, poderá informar o valor 0 (zero) no campo de velocidade na seção 1 . Se isso for feito, a constante 'velocidadeusuario' somará esse zero (variável 'valordois') com a velocidade medida (variável 'valorum'). O que sobra da equação da linha 12 , neste caso, é a velocidade de vento medida pelo usuário e informada na seção 6 .

Além disso, a figura 7 também mostra, na linha 17, a condição criada para considerar no cálculo das dimensões da turbina a carga de eletricidade requerida (potência do gerador eólico). Neste caso o usuário pode optar pela carga gerada a partir de seu preenchimento de equipamentos de consumo na seção 2 , ou informar valores constantes em sua conta de luz. Se os campos da seção 4 (figura 5) não forem preenchidos, o sistema considerará sempre a carga definida na seção 2 e mostrada na seção 3 (ver figura 4).

As simulações feitas até então retornam com dimensões para uma turbina nominal que supriria toda demanda do usuário. Porém existem turbinas com dimensões e características próprias no mercado, e esse tipo de equipamento foi considerado na seção 7 do aplicativo. Nesta parte (apresentada na figura 8) o usuário poderá optar por uma turbina existente com dimensões estabelecidas e saber 0 quanto essa turbina lhe fornecerá de energia, ou seja, qual porcentagem irá suprir, qual o investimento necessário e informações sobre o retorno financeiro do investimento.

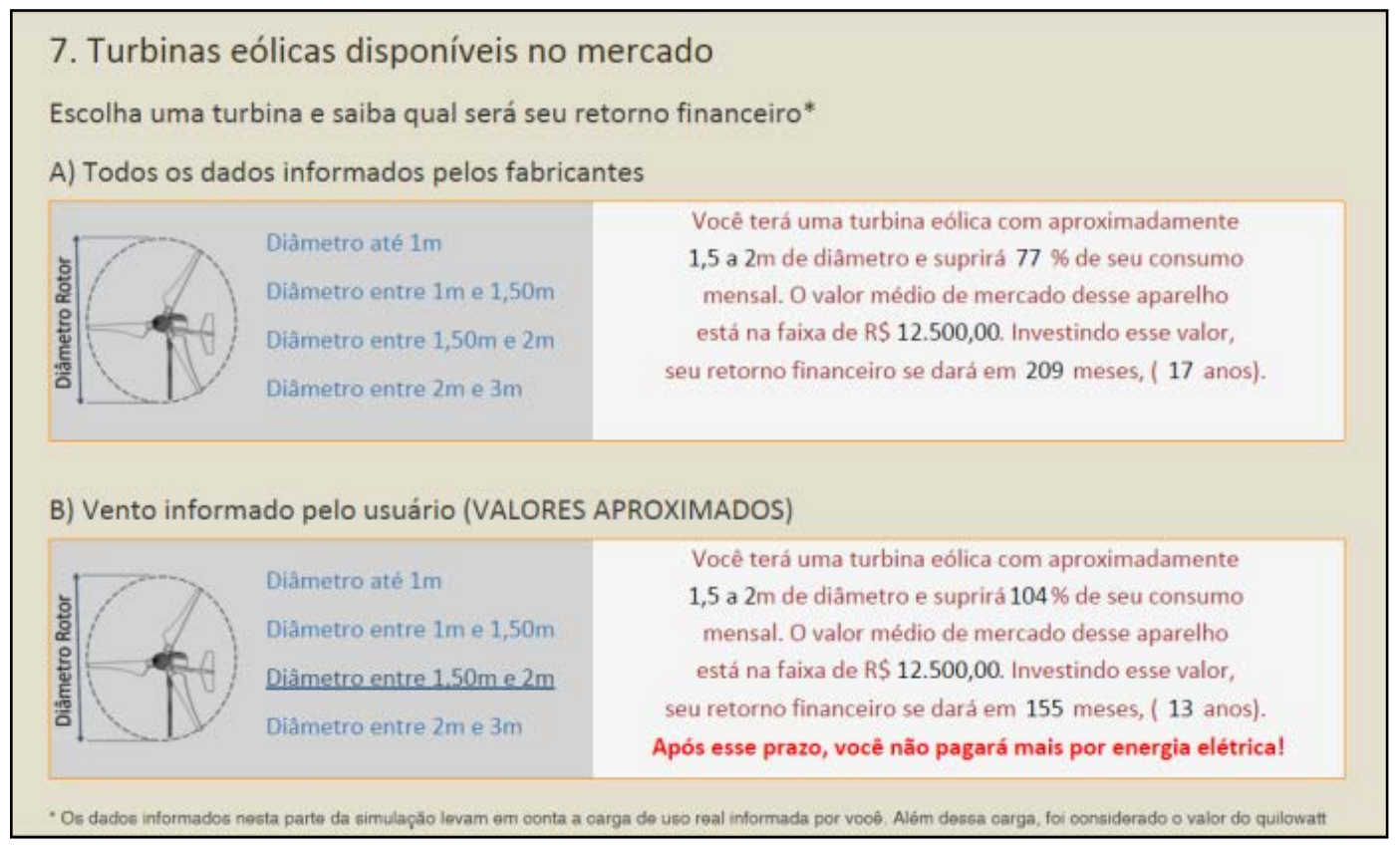

Figura 8 - Resultados de turbinas eólicas

Fonte: Elaborado pelo autor, com base na pesquisa realizada

O principal indicador que diferencia uma turbina de outra, adotado nesta pesquisa, é o diâmetro do rotor. O diâmetro do rotor (duas vezes o comprimento da pá) é determinante para a quantidade de energia que o gerador será capaz de 
converter. Por isso, foram definidas quatro opções de tamanho de turbina para que sejam simuladas. As simulações desta seção informam situações de turbinas reais. As simulações anteriores, nas seções 5 e 6 foram definidas para informar as dimensões de turbinas para suprir $100 \%$ da carga informada pelo usuário, tanto pela média da conta de luz (seção 4) quanto nos dados da instalação elétrica (seção 2).

As simulações desta Seção foram divididas em Parte A e Parte B. Na parte A, as opções de simulação consideram dados de fabricantes e são:

- Diâmetro até $1 \mathrm{~m}$ : Simulação cruzando os dados informados pelo usuário com os de uma turbina genérica. Estas turbinas geralmente não são indicadas para conexão na rede elétrica de concessionárias de energia, convertendo aproximadamente 50 quilowatts hora por mês de energia com vento nominal $(12 \mathrm{~m} / \mathrm{s})$, ou seja, melhor funcionamento. Nesta simulação foi considerado um fator de decréscimo de 0.8 kWh para cada metro por segundo diferente de 12 , para cima e para baixo, a partir de $3 \mathrm{~m} / \mathrm{s}$ chegando ao limite de $20 \mathrm{~m} / \mathrm{s}$.

- Diâmetro entre $1 \mathrm{~m}$ e 1,50m: Simulação cruzando os dados informados pelo usuário com os de uma turbina genérica. Algumas destas turbinas podem ser indicadas para conexão na rede elétrica de concessionárias de energia, dependendo das especificações do fabricante. Este equipamento converte aproximadamente 63 quilowatts hora por mês de energia com vento nominal $(12 \mathrm{~m} / \mathrm{s})$, ou seja, melhor funcionamento. Nesta simulação foi considerado um fator de decréscimo de 0.8 kWh para cada metro por segundo diferente de 12, para cima e para baixo, a partir de $3 \mathrm{~m} / \mathrm{s}$ chegando ao limite de $20 \mathrm{~m} / \mathrm{s}$.

- Diâmetro entre $1,5 \mathrm{~m}$ e $2 \mathrm{~m}$ : Simulação cruzando os dados informados pelo usuário com os de uma turbina genérica. Algumas destas turbinas podem ser indicadas para conexão na rede elétrica de concessionárias de energia, dependendo das especificações do fabricante. Este equipamento converte aproximadamente 85 quilowatts hora por mês de energia com vento nominal $(12 \mathrm{~m} / \mathrm{s})$, ou seja, melhor funcionamento. Nesta simulação foi considerado um fator de decréscimo de 0.8 kWh para cada metro por segundo diferente de 12, para cima e para baixo, a partir de $3 \mathrm{~m} / \mathrm{s}$ chegando ao limite de $20 \mathrm{~m} / \mathrm{s}$.

- Diâmetro entre $2 \mathrm{~m}$ e $3 \mathrm{~m}$ : Simulação cruzando os dados informados pelo usuário com os de uma turbina genérica. Muitas destas turbinas podem ser indicadas para conexão na rede elétrica de concessionárias de energia, dependendo das especificações do fabricante. Este equipamento converte aproximadamente 1497 quilowatts hora por mês de energia com vento nominal $(16 \mathrm{~m} / \mathrm{s})$, ou seja, melhor funcionamento. Nesta simulação foi considerado um fator de decréscimo de 0.8 kWh para cada metro por segundo diferente de 16, para cima e para baixo, a partir de $3 \mathrm{~m} / \mathrm{s}$ chegando ao limite de $20 \mathrm{~m} / \mathrm{s}$.

Na parte $B$, as opções de tamanho de rotor são as mesmas. O que difere é o método de cálculo. Nesta parte, foram aplicadas equações que consideram situações ideais de conversão de energia, não sendo levados em conta dados de fabricantes de turbinas eólicas.

\section{AVALIAÇÃO DE USO E CONCLUSÕES PARCIAIS}

O sistema foi submetido à avaliação através de uma pesquisa formulada com a ferramenta Google Formulários, em que é possível criar um formulário com perguntas 
e opções de respostas. O acesso ao formulário foi colocado no inicio da página de simulação, com um botão contendo o texto: Dê sua opinião, conforme figura 9.

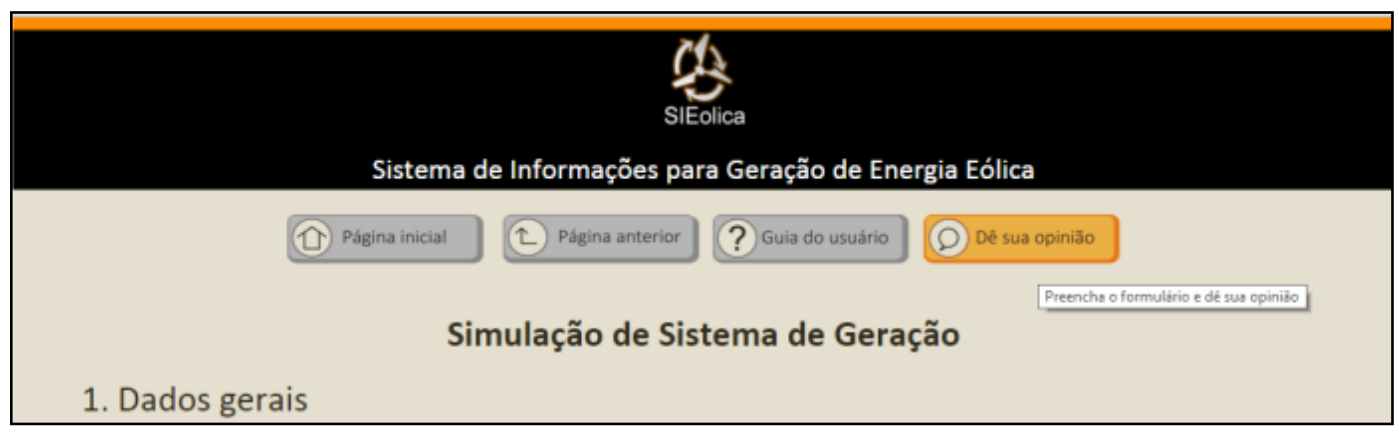

Figura 9 - Botão de acesso ao formulário

Fonte: Elaborado pelo autor, com base na pesquisa realizada

Nesta pesquisa as questões foram elaboradas com os seguintes objetivos:

1. Avaliar a importância do aplicativo no cenário econômico atual do Brasil;

2. Se restaram dúvidas em relação ao aplicativo, após o uso;

3. Verificar se o aplicativo é intuitivo e fácil de usar;

4. Avaliar a influência do aplicativo para o usuário investir em energia eólica.

O aplicativo foi disponibilizado ao público no dia 23 de março de 2016, estando apto à realização de simulações por 40 dias. Durante este período, um número reduzido de respostas ao formulário foi obtido. Por esse motivo e por ainda não se ter os resultados finais da pesquisa, essas respostas serão desconsideradas.

O sistema, além de ser avaliado da maneira descrita, também está sendo monitorado com auxílio da ferramenta Google Analytics. Esta ferramenta consiste em adicionar um código ao arquivo fonte HTML da página que se deseja monitorar. $A$ partir daí é possível obter informações de acessos como quantidade de acessos, tempo de permanência e localização geográfica do acesso à página de internet (tabela 1).

Tabela 1 - Dados de acesso ao sistema

\begin{tabular}{lcl} 
PÁGINA DO SISTEMA & VISUALIZAÇÕES & TEMPO \\
\hline /sieolica/ & 915 & $00: 00: 55$ \\
\hline /sieolica/pagina3.html & 567 & $00: 02: 28$ \\
\hline /sieolica/pagina2.html & 425 & $00: 00: 45$ \\
\hline /sieolica/fluxo.html & 118 & $00: 00: 29$ \\
\hline /sieolica/index.html & 97 & $00: 01: 29$ \\
\hline /sieolica/TEEP.html & 48 & $00: 00: 26$ \\
\hline /sieolica/sobreosautores.html & 43 & $00: 01: 37$ \\
\hline DEMAIS PÁGINAS & 220 & $00: 01: 17$ \\
\hline
\end{tabular}

Fonte: Elaborado pelo autor, com base na pesquisa realizada

O tempo médio de permanência na página3, que é onde se encontra o aplicativo de simulação propriamente dito, foi de quase dois minutos e meio. Este tempo é considerado suficiente para realização de uma simulação. Por meio desta informação conclui-se que foram realizadas, no prazo de 40 dias, 567 simulações.

Neste mesmo prazo de 40 dias, o sistema teve 2433 visualizações em 14 países (88 cidades). Os números obtidos foram impulsionados por um programa de 
divulgação que incluiu sítios de notícias de duas universidades, de órgãos oficiais e associações que tratam do setor de energia no Brasil, além de publicações em rede social. Toda a divulgação foi realizada sem despesa alguma de qualquer parte, caracterizando divulgação de tema de pesquisa acadêmica.

A organização de dados para gerar um sistema de informações resume o conceito de design da informação. A utilização deste conceito para elaborar o sistema aqui proposto possibilitou uma sistematização de fases de desenvolvimento de produto, culminando no aplicativo de simulação que obteve os resultados acima apresentados, considerados apropriados para divulgação dos benefícios da geração distribuída e geração compartilhada de energia elétrica.

Em relação à interface do usuário no aplicativo, pretende-se dar continuidade nos estudos relativos à usabilidade e Interação Humano-Computador (IHC). Este campo de pesquisa é, atualmente, bastante estudado, inclusive sob a ótica do design. Neste sentido, esta parte da pesquisa poderá ser realizada posterior a etapa de avaliações de eficiência e funcionalidades do sistema proposto.

Salienta-se, por fim, da importância para pesquisa em design do registro de patente ou propriedade intelectual de inventos de qualquer natureza, que detenham certo grau de importância. O sistema de informação desenvolvido e apresentado nesta pesquisa teve seu pedido de registro, na modalidade Registro de Software junto ao INPI - Instituto Nacional de Propriedade Intelectual, através de um órgão próprio para essa atividade. $O$ referido pedido encontra-se em tramitação junto ao INPI.

\section{REFERÊNCIAS}

AGUILAR, Luis J. Fundamentos de programação: algoritmos, estrutura de dados e objetos. São Paulo: McGraw-Hill, 2008.

BAXTER, M. Projeto de Produto, Guia Prático para o design de novos produtos. Inglaterra: Edgard Blucher, 2011.

BRASIL, Agencia Nacional de Energia Elétrica. Banco de Informações de Geração. 2016. Disponível na internet em: <http://www.aneel.gov.br>. Acesso em 21 jan. 2016.

BRASIL, Agencia Nacional de Energia Elétrica. Resolução no 482 de 17 de abril de 2012 Estabelece as condições gerais para o acesso de microgeração e minigeração distribuída aos sistemas de distribuição de energia elétrica, o sistema de compensação de energia elétrica, e dá outras providências. Disponível na internet em: <http://www.aneel.gov.br>. Acesso em 16 jul. 2014.

BRASIL, CGEE Centro de Gestão e Estudos Estratégicos (Org.). Redes elétricas inteligentes: contexto nacional. Brasília: Tatiana de Carvalho Pires, 2012.

FRIEDMAN, Ken. Theory construction in design research: criteria: approaches, and methods. Design Studies, 2003, v.24, p. 507-522.

GWEC - Global Wind Energy Council. Global Wind 2013 Report. Belgica: Ed. Lauha F. et al, 2013.

HORN, Robert E. Information Design: Emergence of a new profession. In: Information Design. Cambridge: MIT Press, 1999. P. 15-33.

PIRES, Júlio C.P. Estudo de rotor para turbina eólica de eixo horizontal de pequeno porte com aplicação de modelagem e simulação virtual. 2011, 102 f. Dissertação 
(mestrado) - Universidade Federal do Rio Grande do Sul, curso de pós-graduação em Design. 